\title{
Investigation of alveolar macrophage function using lucigenin-dependent chemiluminescence
}

\author{
ANDREW J WILliams, PETER J COLE \\ From the Host Defence Unit, Department of Medicine, Cardiothoracic Institute, Brompton Hospital, London
}

\begin{abstract}
A method using lucigenin-dependent phagocytic chemiluminescence is described for the assessment of alveolar macrophage metabolic activity in response to stimulation by opsonised particles or soluble agents. The requirement for superoxide anion $\left(\mathrm{O}_{2}^{-}\right)$in the production of chemiluminescence is suggested by inhibition $(95 \%)$ using superoxide dismutase. The results obtained are correlated with those obtained using another method of detecting $\mathrm{O}_{2}^{-}$release $(\mathrm{r}=0.61 ; \mathrm{p}<0.05)$ and are also related by regression analysis to polymorphonuclear leucocyte contamination of the alveolar macrophage suspension. This shows that alveolar macrophages produce lucigenin-dependent chemiluminescence of the same order of magnitude as do polymorphonuclear leucocytes.
\end{abstract}

The alveolar macrophage (AM) is the resident phagocytic cell in the lower respiratory tract and a role for its involvement in the aetiology of various diseases has been demonstrated. ${ }^{1}$ Stimulation of the cell membrane either by adherence of opsonised particles or by soluble agents such as the co-carcinogen phorbol myristate acetate leads to the increased production of hydrogen peroxide and superoxide anion $\left(\mathrm{O}_{2}{ }^{-}\right){ }^{2}$ In addition to being important microbicidal agents, these reactive substances and their products have been implicated in the pathogenesis of respiratory membrane damage in paraquat poisoning $^{3}$ and after exposure to high concentrations of oxygen. ${ }^{4}$

Bronchoalveolar lavage during fibreoptic bronchoscopy harvests human alveolar macrophages but methods investigating phagocytic metabolic activity often require more cells than are obtained by this technique. Luminol-dependent chemiluminescence, which requires comparatively few cells, has been used as an assay of phagocytic oxidative metabolism in polymorphonuclear leucocytes and for investigation of the opsonic activity of serum. ${ }^{5}$ Luminol (5-amino-2,3-dihydro-1,4-phthalazinedione), a cyclic hydrazide, releases light when oxidised by the reactive species produced by polymorphonuclear leucocytes and monocytes. ${ }^{6}$ Although the specific reaction mechanism is not known, a requirement for

Address for reprint requests: Dr AJ Williams, Host Defence Unit, Department of Medicine, Cardiothoracic Institute, Brompton Hospital, Fulham Road, London SW3 6HP. myeloperoxidase is evident. ${ }^{7}$ Probably because of the very low peroxidase activity in human $\mathrm{AM},{ }^{8}$ the technique is not of use in the investigation of these cells obtained by bronchoalveolar lavage. ${ }^{9}$ In contrast, lucigenin (dimethylbiacridinium nitrate) ${ }^{10}$ does not require peroxidase activity for the production of light as a result of reduction by the reactive species produced by phagocytic cells. Furthermore, the response is almost completely suppressed by superoxide dismutase suggesting dependence upon $\mathrm{O}_{2}{ }^{-}$.

Here we outline a method for the measurement of lucigenin-dependent chemiluminescence by human alveolar lavage cells and compare the results with those obtained using an alternative method of $\mathrm{O}_{2}$ estimation.

\section{Methods}

Alveolar macrophages were obtained at fibreoptic bronchoscopy by bronchoalveolar lavage with bicarbonate buffered $0.9 \%$ sodium chloride from 24 patients with diagnoses of sarcoidosis $(n=10)$ cryptogenic fibrosing alveolitis $(n=10)$, asbestosis $(n=1)$, extrinsic allergic alveolitis $(n=3)$, as well as from four patients under investigation for haemoptysis. Informed written consent was obtained from all patients. After centrifugation $\left(150 \mathrm{~g}\right.$ at $\left.4^{\circ}\right)$ for five minutes, the alveolar lavage cells were washed with tissue culture medium at $4^{\circ}$ and resuspended in medium (medium 199 without phenol red; Flow Laboratories) to a concentration of $4 \times 10^{5}$ $\left(10^{6}\right.$ for $\mathrm{O}_{2}-$ estimation) nonspecific esterase positive 
cells per ml. ${ }^{11}$ The suspension was kept on ice in a siliconised glass container until use. Differential cell counts using May-Grunewald giemsa-stained cytocentrifuge preparations were performed on all specimens. Macrophage cell viability was assessed by trypan blue exclusion and exceeded $90 \%$ in all cases. Serum from five apparently healthy donors was pooled and stored in aliquots at $-70^{\circ}$.

Zymosan $(10 \mathrm{mg} / \mathrm{ml}$; Sigma) was opsonised by incubation at $37^{\circ}$ for 30 minutes with $20 \%$ serum. Phorbol myristate acetate (Sigma) was dissolved in dimethylsulfoxide $(1 \mathrm{mg} / \mathrm{ml})$ and then diluted in phosphate buffered saline (1:2000). Lucigenin $\left(10^{-4} \mathrm{M}\right.$; Sigma) was dissolved in Hanks's balanced salt solution buffered with $20 \mathrm{mM}$ HEPES (N-2hydroxyethylpiperazine- $\mathrm{N}$-2-ethanesulphonic acid).

Chemiluminescence was measured at $37^{\circ}$ using a photometer (Luminometer 1250; LKB Wallac). The alveolar macrophage suspension $(500 \mu \mathrm{l})$ was added to lucigenin $(900 \mu \mathrm{l})$ with $0.1 \%$ gelatin in a reaction vial which was placed in the carousel of the photometer. Opsonised zymosan suspension $(100 \mu \mathrm{l})$ or phorbol myristate acetate $(100 \mu \mathrm{l})$ was added to the mixture and the light produced was monitored graphically on a chart recorder (LKB-Bromma 2210). The reading 12 minutes after addition of particles or soluble stimulant was used for analysis.

Superoxide anion release was estimated by superoxide dismutase inhibitable ferricytochrome $\mathrm{C}$ reduction. ${ }^{12}$ Opsonised zymosan $(100 \mu \mathrm{l})$ or phorbol myristate acetate $(100 \mu \mathrm{l})$ was added to $1.5 \mathrm{ml} \mathrm{AM}$ suspension $\left(10^{6}\right.$ cells $/ \mathrm{ml}$ with $0.1 \%$ gelatin $)$ in the presence of $26 \mathrm{mM}$ oxidised ferricytochrome C (horse heart type VI; Sigma). The vials were incubated at $37^{\circ}$ for 15 minutes in parallel with vials that in addition contained superoxide dismutase (60 $\mu \mathrm{g} / \mathrm{ml}$; Sigma). After incubation the suspension was centrifuged ( $4000 \mathrm{~g}$ for 10 minutes) and, using the supernatant, $\mathrm{O}_{2}{ }^{-}$release was estimated spectrophotometrically at $550 \mathrm{~nm}$ (extinction coefficient = $\left.21 \cdot 1 \mathrm{mM}^{-1} \mathrm{~cm}^{-1}\right)$.

\section{Results and discussion}

The burst of metabolic activity that occurs as a result of membrane stimulation in phagocytic cells can be triggered by soluble agents, such as phorbol myristate acetate, as well as by adherence of particles opsonised by immunoglobulin or the $\mathrm{C}_{3} \mathrm{~b}$ fraction of complement as is the case with zymosan. The presence of polymorphonuclear leucocytes $(\mathrm{PMN})$ in alveolar lavage specimens is a feature of several disease states, ${ }^{13}$ and currently there is no suitable method for separating the cells without altering AM function. Consideration of these cells needs to be made when investigating AM metabolic activity.

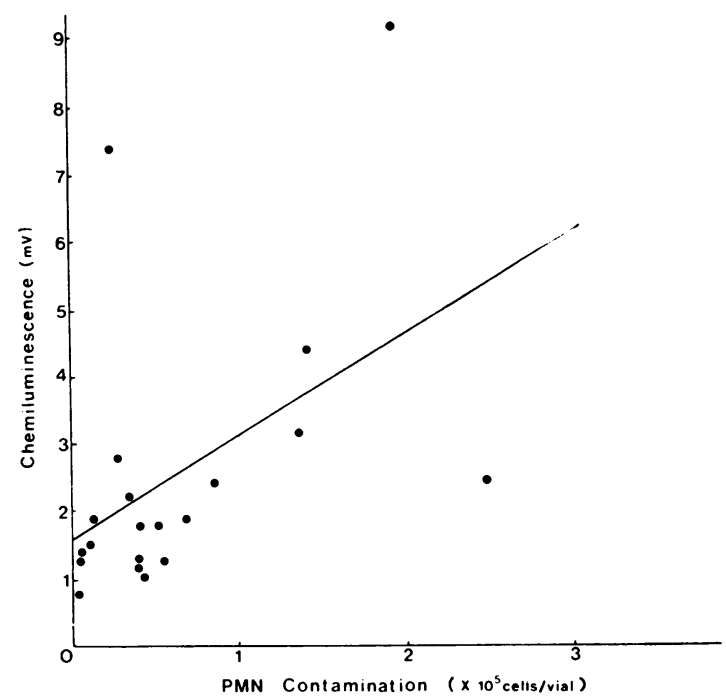

(a)

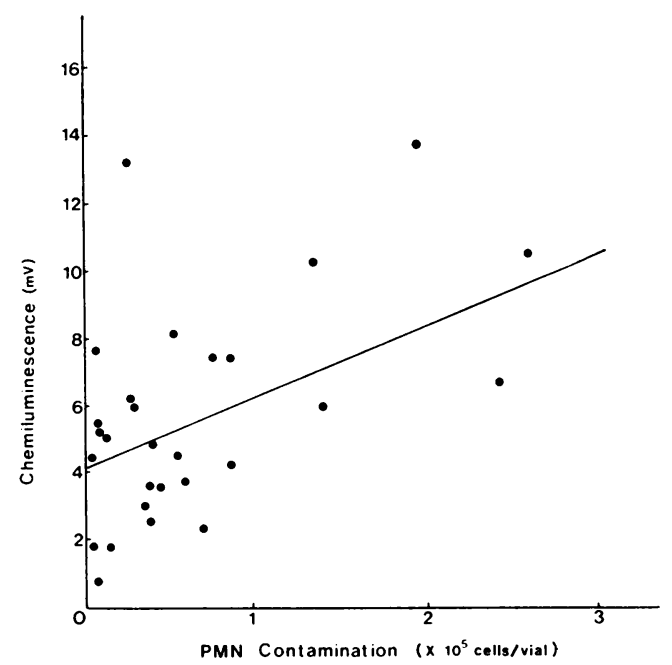

(b)

Fig 1 Relationship between lucigenin-dependent chemiluminescence response and polymorphonuclear leucocyte $(P M N)$ contamination of alveolar macrophage suspension when stimulated by (a) phorbol myristate acetate and (b) opsonised zymosan.

Figure 1 shows the correlation between the number of PMN present in the AM suspension and the chemiluminescent response on stimulation of lavage cells by either phorbol myristate acetate or opsonised zymosan. PMN contribute to the light production but regression analysis shows that the individual 


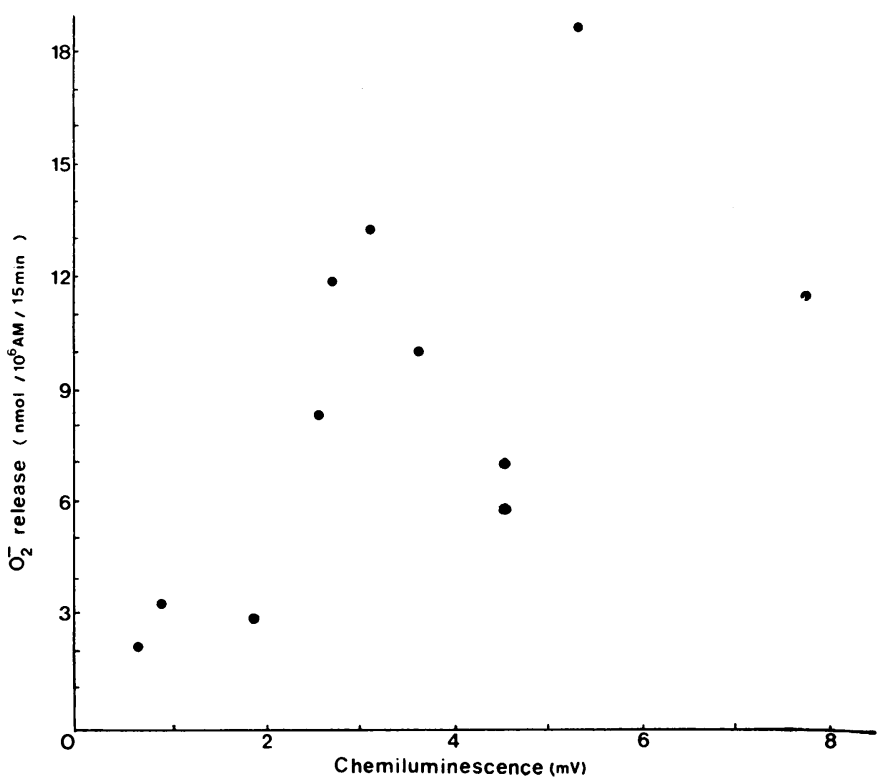

Fig 2 Relationship between lucigenindependent chemiluminescence response and superoxide anion $\left(\mathrm{O}_{2}^{-}\right)$release on addition of opsonised zymosan to alveolar macrophage suspensions.

AM response is of the same order of magnitude (Zymosan: Chemiluminescence $(\mathrm{CL})(\mathrm{mV})=4.22$ $+\left(2.38 \times\right.$ PMN $\times 10^{-5} /$ vial $) ;$ Phorbol myristate acetate: $\left.\mathrm{CL}=1.60+\left(1.55 \times \mathrm{PMN} \times 10^{-5} / \mathrm{vial}\right)\right)$. This is in contrast to the situation with luminoldependent chemiluminescence..$^{9}$ There is no correlation $(\mathrm{r}=0.003 ; \mathrm{n}=28)$ with lymphocyte contamination and this observation is supported by the absence of response when using a purified lymphocyte preparation from peripheral blood.

Lucigenin-dependent phagocytic chemiluminescence is more than $95 \%$ suppressed by superoxide dismutase $(30 \mu \mathrm{g} / \mathrm{ml})$ implicating the involvement of $\mathrm{O}_{2}-$ in its production. Figure 2 shows the correlation (correlation coefficient $=0.61, \mathrm{p}<0.05$ ) between chemiluminescence and $\mathrm{O}_{2}-$ production as measured by ferricytochrome $\mathrm{C}$ reduction $(\mathrm{n}=11)$. This technique differs in that measurements are made upon the supernatant after a period of incubation followed by centrifugation - that is, after production of the $\mathrm{O}_{2}-$-because particles and cells interfere with the spectrophotometric assay. In contrast, the chemiluminescence assay can be used to monitor $\mathrm{O}_{2}{ }^{-}$ production as it occurs. This can be of benefit when assessing the interaction between membrane receptor sites on the phagocytic cell and opsonins coating the particles. ${ }^{14}$

The importance of oxygen radical production by phagocytic cells, both as a microbicidal mechanism and as a pathogenetic factor in respiratory membrane damage, has provoked interest in the assessment of AM metabolic activity. We have shown that AM produce lucigenin-dependent chemiluminescence when stimulated and suggest that this technique may prove useful in the assessment of AM function in different disease states.

We are grateful to Fiona Allen and Professor $\mathbf{M}$ Turner-Warwick. AJW is supported by a grant from Abbott Laboratories Limited. This work is supported by a grant from The Wellcome Trust. We thank LKB for supply of a Luminometer.

\section{References}

${ }^{1}$ Hocking WG, Golde DW. The pulmonary-alveolar macrophage. $N$ Engl J Med 1979;301:580-7.

2 Gee JBL, Khandwala AS. Oxygen metabolism in the alveolar macrophage; friend or foe? $J$ Reticuloendothel Soc 1976;19:229-36.

${ }^{3}$ Autor AP, ed. Biochemical mechanisms of paraquat toxicity. New York: Academic Press, 1977.

4 Frank L, Massaro D. Oxygen toxicity. Am J Med 1980; 69:117-26

- Williams AJ, Hastings MJG, Easmon CSF, Cole PJ. Factors affecting the in vitro assessment of opsonization: a study of the kinetics of opsonization using the technique of phagocytic chemiluminescence. Immunology 1980; 41 :903-11

- Allen RC, Loose LD. Phagocytic activation of a luminoldependent chemiluminescence in rabbit alveolar and peritoneal macrophages. Biochem Biophys Res Commun 1976;69:245-52.

' Stevens P, Winston DJ, Van Dyke K. In vitro evaluation of opsonic and cellular granulocyte function by luminoldependent chemiluminescence: utility in patients with severe neutropenia and cellular deficiency states. Infect Immun 1978;22:41-51. 
${ }^{8}$ Biggar WD, Sturgess JM. Peroxidase activity of alveolar macrophages. Lab Invest 1976;34:31-42.

- Williams AJ, Cole PJ. Human bronchoalveolar lavage cells and luminol-dependent chemiluminescence. $J$ Clin Pathol 1981; 34:167-71

10 Greenlee LL, Fridovich I, Handler P. Chemiluminescence induced by operation of iron flavoproteins. Biochemistry 1962;1:779-83.

11 Yam LT, Li CY, Crosby WH. Cytochemical identification of monocytes and granulocytes. Am J Clin Pathol 1970; 55:283-90.
12 Babior BM, Kipnes RS, Curnutte JT. The production by leukocytes of superoxide, a potential bactericidal agent. $J$ Clin Invest 1973;52:741-4.

13 Hunninghake GW, Gadek JE, Kawanami O, Ferrans VJ, Crystal RG. Inflammatory and immune processes in the human lung in health and disease: evaluation by bronchoalveolar lavage. Am J Pathol 1979;97:149-206.

14 Allen RC. Evaluation of serum opsonic capacity by quantitating the initial chemiluminescent response from phagocytizing polymorphonuclear leukocytes. Infect Immun 1977;15:828-33. 